\title{
MELHORIAS EM ESTAÇÃO DE TRATAMENTO DE ÁGUAS DE INDÚSTRIA BENEFICIADORA DE ARROZ
}

\author{
C. BIRON ${ }^{1}$, C. O. MEDEIROS ${ }^{1}$, J. V. DIEL ${ }^{1}$, K. L. BUENO ${ }^{1}$, L. M. RODRIGUES ${ }^{1}$, R. A. \\ MARTINS ${ }^{1}$, R. R. LIMA ${ }^{1}$ e T. R.de SOUZA ${ }^{1}$ \\ 1 Universidade Federal do Pampa, Departamento de Engenharia Química \\ E-mail para contato: tania.souza31@hotmail.com
}

\begin{abstract}
RESUMO - No cenário atual a água pode ser considerada um fator determinante no desenvolvimento de uma região e, por consequência, o seu tratamento tem fundamental importância. Particularmente, em indústrias beneficiadoras de arroz parboilizados, a água de processo determina a qualidade do produto final, bem como facilita o tratamento do efluente gerado. Assim, este artigo tem como objetivo desenvolver um estudo de implantação de melhorias na estação de tratamento de águas de uma indústria beneficiadora de arroz na região da Campanha que apresenta inúmeros equívocos em seu tratamento prejudicando a produção. A metodologia utilizada envolveu o desenvolvimento de uma nova planta com equipamentos devidamente dimensionados e que se adequassem a demanda de produção atual da empresa. $\mathrm{O}$ estudo trouxe como implantações à planta um sistema de agitação, antes inexistente, modificações na captação de afluente pré-clarificado e inserção de tanque pulmão. As sugestões previamente testadas promovem maior qualidade na água de processo e maior eficiência no produto final.
\end{abstract}

\section{INTRODUÇÃO}

Com o crescimento desordenado das cidades a água torna-se cada vez mais uma preocupação, mesmo em cidades onde haja abundância de recursos hídricos. A água está se tornando um fator limitante para o desenvolvimento econômico de uma região.

O tratamento de água passa então a ser considerado de fundamental importância, seja para indústrias ou abastecimento residencial. Esse tratamento deve atender as normativas e assim garantir que alguns parâmetros físico-químicos sejam atendidos, propiciando uma água de boa qualidade a todos.

Um estudo de melhorias, adequação ou otimização de uma estação de tratamento de águas e efluentes requer o conhecimento das características associadas ao afluente. Von Sperling (2005) afirma que as características químicas estão relacionadas com a origem e o $\mathrm{pH}$ do afluente, que indica acidez, neutralidade ou alcalinidade. Já as características biológicas envolvem a existência de microorganismos indicadores de poluição, variações de vazão, entre outros.

Admitindo as características da água de processo a ser empregada na indústria, pode-se traçar o ciclo de tratamento que promove a qualidade sanitária e econômica, tornando-a apta para utilização no processo. Segundo Fontana (2004), tratamentos de ciclo completo, também chamado de convencional, tipificam-se pela captação de água bruta em mananciais superficiais e adição de produtos químicos para adequação.

Fontana (2004) ainda diz que normalmente são utilizados como coagulante sais de ferro ou alumínio, que através de cargas elétricas promovem a desestabilização das partículas. 
Entretanto, para que o floco seja formado através desses sais é necessária agitação rápida para dispersão do coagulante e posterior agitação lenta para formação dos flocos (floculação). Estes flocos podem ser removidos com a utilização de decantadores que realizam a separação sólido-líquido. Então os flocos são retidos no fundo do sedimentador, formando o lodo, que tradicionalmente são eliminados por um sistema de descarga. A água pré-clarificada ainda contendo flocos é encaminhada para filtros que realizam a clarificação final, e assim tem-se água padronizada para abastecimento.

Porém, para ter uma execução apropriada de tratamento de afluentes é necessário que a estrutura física da planta apresente condições de operação adequadas ao tratamento. Uma das primeiras considerações a ser feita é a utilização de sistemas agitados, pois de acordo com Cremasco (2012) a agitação promove o incremento das taxas de transferência de calor e de massa, bem como facilita a ocorrência de reações químicas.

Além disso, Cremasco (2012) ainda explana que o sistema de agitação é composto de um tanque ou reservatório e acessórios, como impelidores e chicanas ou defletores. Os impelidores transmitem movimento e consequentemente mistura ao fluido, enquanto que as chicanas são chapas utilizadas no interior do reservatório para o redirecionamento do fluxo de mistura, eliminando a possibilidade de vórtice.

Segundo McCabe (2005) a forma de agitação de um líquido em um vaso está intimamente ligada ao tipo de impelidor, às características do líquido, especialmente a viscosidade, além do tipo e proporção (dimensões) do tanque.

Para fluidos de baixa viscosidade (até $3000 \mathrm{cP}$ ), faixa de rotação de 20 a $200 \mathrm{rpm}$ e com características de fluxo axial e radial, o impelidor apropriado de acordo com Geankoplis (2003) é do tipo Remo (Paddle). Para baixas rotações a associação do impelidor remo com chicanas não é requerido, o que não acontece para altas rotações.

De acordo com Cremasco (2012), os impelidores do tipo Paddle podem conter pás inclinadas. Pás com inclinação de $45^{\circ}$ provocam um fluxo predominantemente axial, condição ideal de aplicação para casos de suspensão de sólidos.

Outrossim, para auxiliar no tratamento, o emprego de tanque pulmão contribui como um fator de segurança na distribuição de afluente para as linhas de processo. Seydell (2008) especifica o tanque pulmão como um dispositivo de auxílio responsável pela armazenagem de efluente em casos de paradas para manutenção na estação. $O$ dimensionamento deste tanque está relacionado ao tempo de parada no processo. Ademais, a unidade deve conter um revestimento de manta impermeável que impeça vazamentos.

\section{OBJETIVOS}

Este estudo tem por objetivo promover melhorias na estrutura física da planta da estação de tratamento de águas de Indústria de Beneficiamento de Arroz na região da Campanha a fim de proporcionar aumento na eficiência e confiabilidade na obtenção do produto final.

\section{MATERIAIS E MÉTODOS}

Para o desenvolvimento da planta de Estação de Tratamento de Águas foi utilizado o programa Microsoft Office Visio versão 2007. Enquanto que para avaliar as condições de operação da estação foram realizados monitoramentos semanalmente, cerca de 2 a 3 vezes, durante 4 meses, para avaliar a capacidade de produção, localização de equipamentos e 
instrumentos, assim como eventuais problemas na planta e impactos econômicos e ambientais gerados ou que possam futuramente ser gerados.

Foram utilizados no monitoramento semanal, basicamente, pHmetro, recipientes para a coleta de água e areia, trena e equipamentos de proteção individual.

Com base nas informações adquiridas, pode-se dimensionar o tamanho dos tanques dosadores de produtos, o tipo e parâmetros de agitação dos agitadores e, ainda, a capacidade do tanque pulmão.

\subsection{Metodologia de Cálculo}

Para obter a potência requerida pelo agitador utiliza-se a correlação empírica que relaciona o número de Reynolds do impelidor e o número de potência. Esta correlação é apresentada graficamente pela Figura 1 .

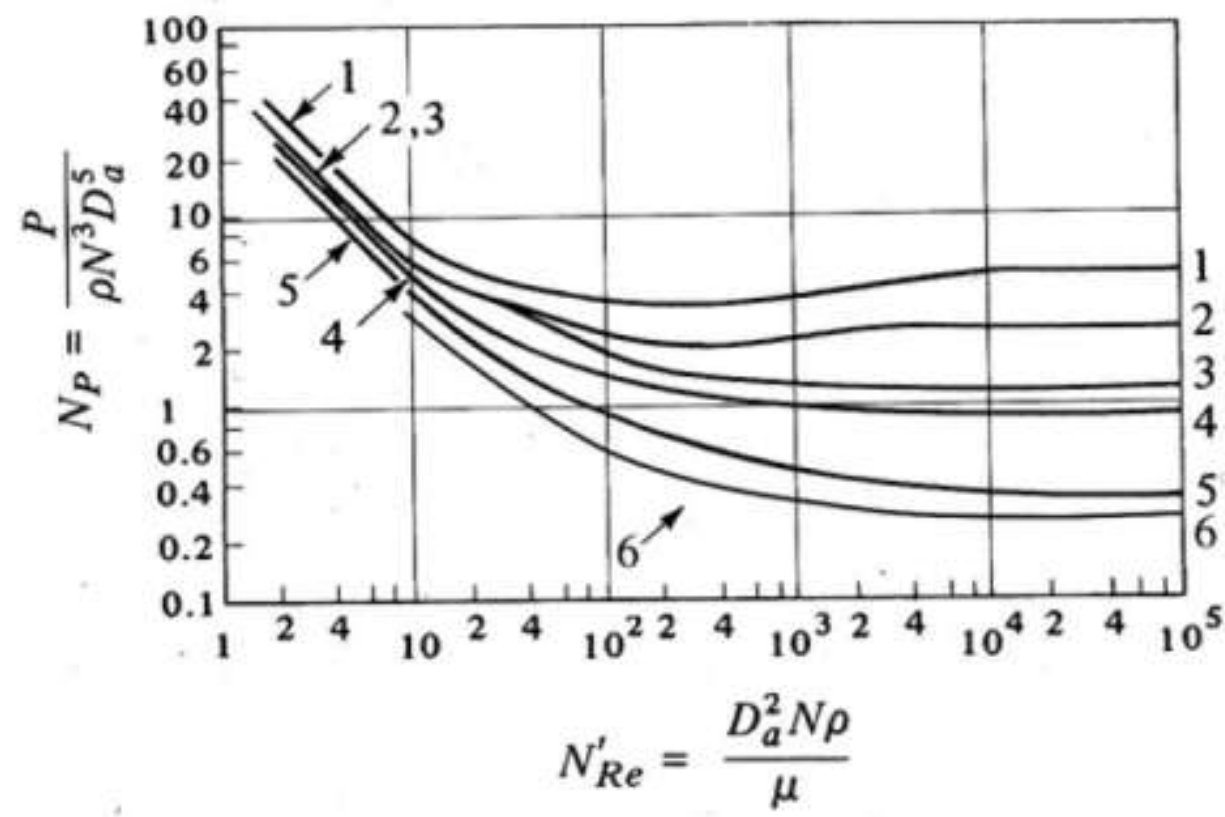

Figura 1- Correlação do Número de Reynolds e o Número dede Potência do Agitador. Fonte: Cremasco (2012).

Através da Figura 1 é possível obter o número de potência para seis tipos de agitadores. O número 1 corresponde ao agitador do tipo turbina com disco e seis pás, o número 2 indica agitador turbina aberta com seis pás, o número 3 representa turbina aberta com seis pás de $45^{\circ}$, o número 4 representa hélice com espaçamento duas vezes maior que o diâmetro do agitador, enquanto que o número 5 tem o espaçamento igual ao diâmetro do agitador. Por fim, o número 6 representa hélice de alta eficiência com razão diâmetro do tanque e largura da chicana correspondente a 12 .

Assim, o número de Reynolds deve ser calculado pela Equação 1.

$$
N^{\prime} r e=\frac{D a^{2} N \rho}{\mu}
$$

em que N're é o número de Reynolds, $D a$ o diâmetro do agitador, $N$ a velocidade rotacional, $\rho$ a massa específica do fluido e $\mu$ a viscosidade dinâmica do fluido. 
Enquanto que o cálculo da potência requerida pode ser expresso pela Equação 2.

$$
N p=\frac{P}{\rho N^{3} D a^{5}}
$$

em que $\mathrm{Np}$ é o número de potência e $\mathrm{P}$ a potência requerida.

Outras correlações podem ser empregadas a fim de obter as dimensões padrões para um sistema agitado. A Equação 3 apresenta a correlação entre diâmetro do agitador e diâmetro do tanque.

$$
\frac{D a}{D t}=0,3 \rightarrow 0,5
$$

onde Dt é o diâmetro do tanque.

A espessura e a largura do agitador podem ser obtidas através das correlações das Equações 4 e 5.

$$
\frac{W}{D a}=\frac{1}{5}
$$

onde W é a espessura da pá (agitador).

$$
\frac{L}{D a}=\frac{1}{4}
$$

onde L é a largura do agitador.

A altura de líquido no reservatório também pode ser calculada e para isto utiliza-se a Equação 6.

$$
\frac{H}{D t}=1
$$

em que H é a altura de líquido.

A distância entre o impelidor e o fundo do tanque deve ser calculada para máxima eficiência na agitação e é obtida pela correlação da Equação 7.

$$
\frac{C}{D t}=\frac{1}{3}
$$

em que C é a distância entre impelidor e fundo do tanque.

Ainda pode ser encontrado o valor para largura da chicana através da Equação 8.

$$
\frac{J}{D t}=\frac{1}{12}
$$

onde J é a largura da chicana. 
Por fim, o tempo de mistura é obtido pela Equação 9.

$$
f_{t}=\frac{t_{t}\left(N D_{a}\right)^{\frac{2}{3}} g^{\frac{1}{6}} D_{a}^{\frac{1}{2}}}{H^{\frac{1}{2}} D_{t}^{\frac{3}{2}}}
$$

onde $f_{t}$ é o fator de mistura, $t_{t}$ é o tempo de mistura, $N$ a velocidade de rotação, $g$ a aceleração da gravidade. mistura.

O tempo de residência tradicionalmente corresponde a dez vezes o valor do tempo de

\section{RESULTADOS E DISCUSSÃO}

O projeto visando a melhor confiabilidade e eficiência econômica e ambiental a partir das medidas obtidas na própria planta da estação de tratamento de águas da empresa, pode ser desenvolvido um esquema de locação e fluxo de afluente dentro do necessário para atender o processo de beneficiamento de arroz. A Figura 2 mostra a planta da situação atual que exemplifica o recebimento e transporte de água bruta proveniente de barragem até a estação de tratamento de águas. Antes de entrar no decantador a água recebe a dosagem de produtos, sendo floculante e auxiliar de floculação. Em seguida, a água com os agentes de sedimentação entram pela parte inferior do decantador formando um "jorro" sendo o clarificado captado na parte lateral inferior do tanque e transferido a filtros.

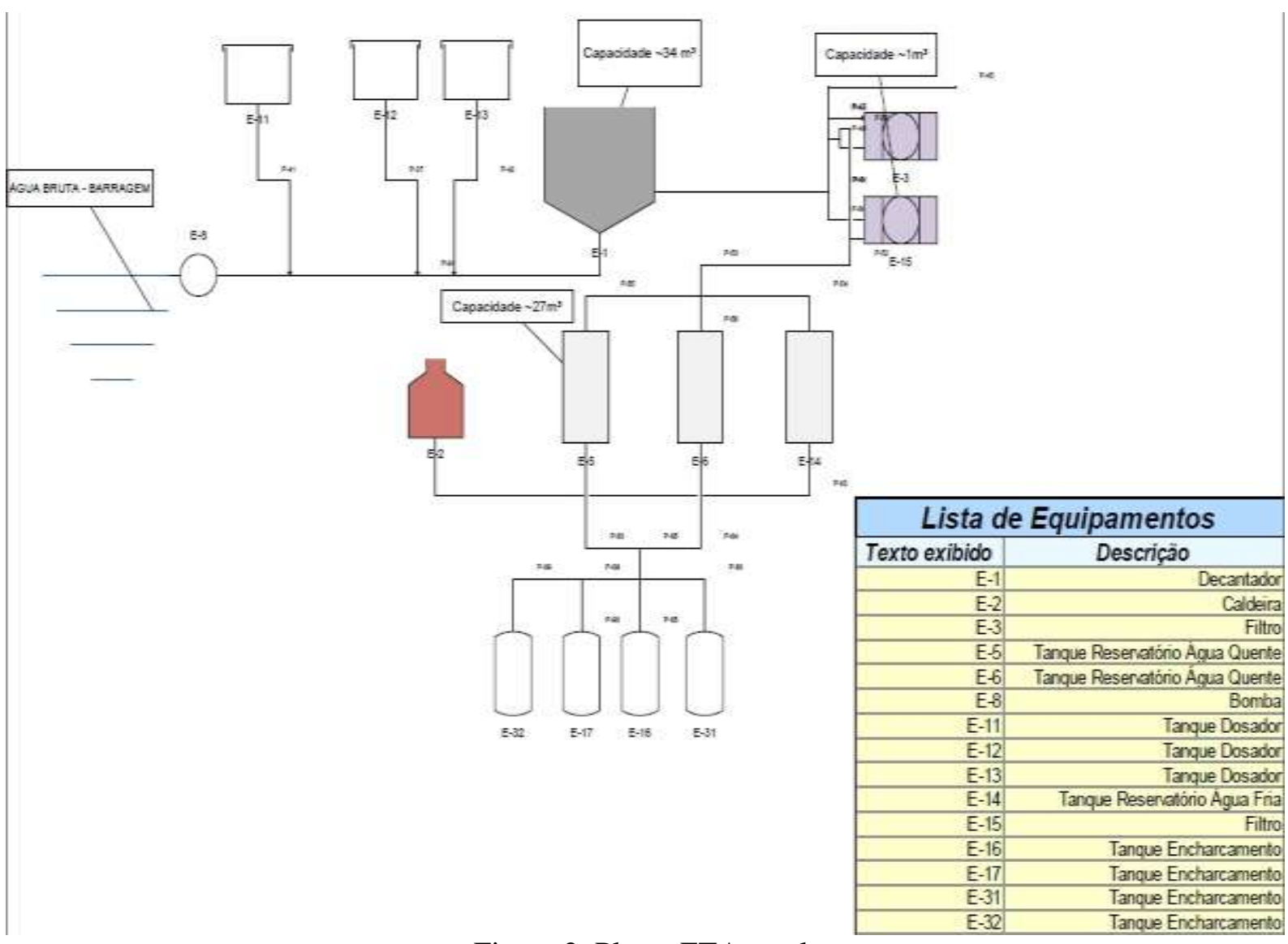

Figura 2: Planta ETA atual 
Depois de filtrada em E-3 da Figura 2, a água previamente tratada é enviada a tanques reservatórios, sendo dois de água quente (E-6 e E-6) e um de água fria (E-14). . Os reservatórios que armazenam água quente liberam água para o processo de encharcamento de arroz (E-16, E-17, E-31 e E-32), enquanto que o reservatório de água fria envia o fluido para a caldeira (E-2).

Após estudar e verificar as incoerências contidas no tratamento de águas da empresa pode-se sugerir modificações na planta, a começar pelos tanques dosadores de produtos, pois os mesmos não apresentam diâmetro adequado para a capacidade de produção. Também se estudou a influência da agitação e tempo de residência suficientes dos produtos em cada tanque para que a formação de flocos e posterior arraste de partículas na decantação seja eficaz.

Quanto ao sedimentador, nota-se que o local de captação de clarificado é próximo da região de lodo espessado, provavelmente a água repassada ao filtro apresenta grande concentração de sólidos, tornando a filtração insuficiente para clarificar a água. Além disto, o filtro apresenta granulometria indefinida, não sendo separado por camadas, mas disposto em uma única camada de areia. Consequentemente, o tratamento não é o adequado para o processo de beneficiamento de arroz.

Assim, a Figura 3 mostra as sugestões de melhorias na estrutura física da estação para tornar o processo mais eficaz.

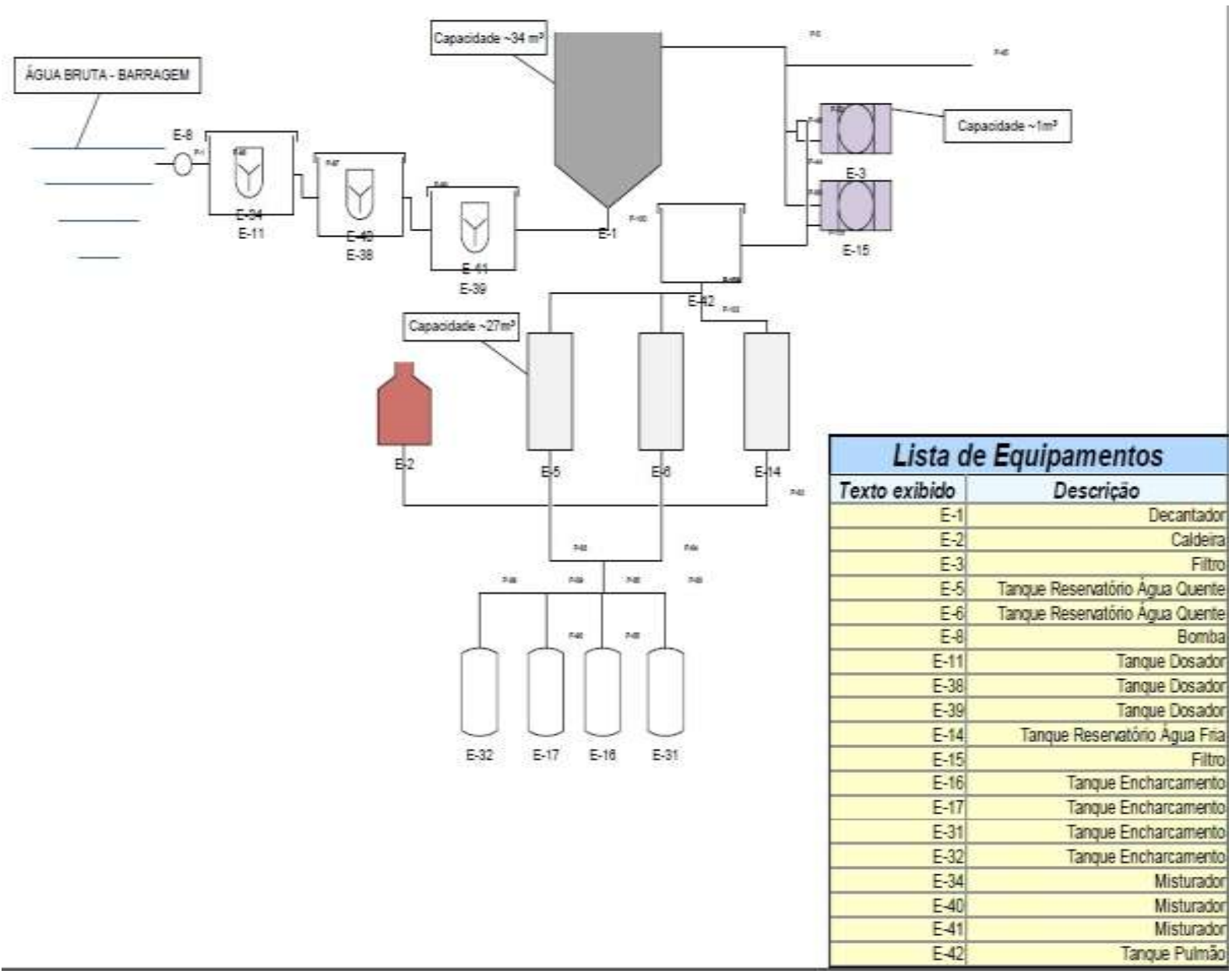

Figura 3: Planta da ETA com sugestões de modificação

$\mathrm{Na}$ Figura 4 podem ser visualizadas as primeiras modificações nos tanques dosadores. $\mathrm{O}$ projeto de adequação propõe vasos comunicantes que não estão no mesmo nível, estando o 
primeiro tanque em um nível mais elevado que o segundo e o segundo tanque um nível acima que o terceiro, excluindo a necessidade de bomba. Estes tanques ainda contêm agitadores de diferentes potências e velocidade de rotação, devendo conter chicanas, de acordo com a necessidade projetada para o tratamento da água da empresa com suas respectivas propriedades.

Partindo para o decantador, constatou-se a necessidade de modificar o local de captação de clarificado, que passa a ser na parte superior do decantador para evitar o arraste de lodo espessado. A descarga de lodo pelo decantador deve ocorrer a cada 5 minutos com a liberação de 3 litros, sendo a bomba peristáltica indicada para este tipo de operação. Para os filtros sugere-se a formação de camadas de areia fina, média e grossa, com granulometria bem definidas para auxiliar no arraste de partículas ainda existentes.

Para intensificar as melhorias na planta é necessária a colocação de um tanque pulmão para atuar como fator de segurança no armazenamento e redistribuição de água nas linhas, com volume de $15 \mathrm{~m}^{3}$ com base na produção diária atual de arroz da empresa, com média de consumo de água de 10 metros cúbicos por hora.

$\mathrm{Na}$ Tabela 1 estão as dimensões e condições de operação para as modificações na planta.

Tabela 1- Dimensões para os Tanques Dosadores de Produtos.

\begin{tabular}{|c|c|c|c|}
\hline & Tanque 1 & Tanque 2 & Tanque 3 \\
\hline Diâmetro & $1,2 \mathrm{~m}$ & $1,2 \mathrm{~m}$ & $1,2 \mathrm{~m}$ \\
\hline $\begin{array}{c}\text { Diâmetro do } \\
\text { comitador (Tipo Remo } \\
\text { pás inclinadas } \\
\text { de 45 })\end{array}$ & $0,4 \mathrm{~m}$ & $0,4 \mathrm{~m}$ & $0,4 \mathrm{~m}$ \\
\hline Altura do Tanque & $1,8 \mathrm{~m}$ & $1,8 \mathrm{~m}$ & $1,8 \mathrm{~m}$ \\
\hline Volume do Tanque & $2 \mathrm{~m}^{3}$ & $2 \mathrm{~m}^{3}$ & $2 \mathrm{~m}^{3}$ \\
\hline Tamanho das Pás & $0,15 \mathrm{~m}$ & $0,15 \mathrm{~m}$ & $0,15 \mathrm{~m}$ \\
\hline $\begin{array}{c}\text { Tamanho das } \\
\text { Chicanas }\end{array}$ & $0,12 \mathrm{~m}$ & $0,12 \mathrm{~m}$ & $0,12 \mathrm{~m}$ \\
\hline $\begin{array}{c}\text { Velocidade de } \\
\text { Rotação }\end{array}$ & $100 \mathrm{rpm}$ & $80 \mathrm{rpm}$ & $20 \mathrm{rpm}$ \\
\hline Potência & $71 \mathrm{~W}$ & $36 \mathrm{~W}$ & $0,5 \mathrm{~W}$ \\
\hline Tempo de Residência & $2,5 \mathrm{~min}$ & $2,90 \mathrm{~min}$ & $9,15 \mathrm{~min}$ \\
\hline
\end{tabular}

Ao analisar a Tabela 1 constata-se que as dimensões do tanque e agitadores são as mesmas, entretanto alguns parâmetros como velocidade de rotação, potência e tempo de residência diferem. As velocidades de rotação para o processo são de 100, 80 e $20 \mathrm{rpm}$ para os vasos 1, 2 e 3, respectivamente. Esta alteração na velocidade de rotação deve-se a função que cada tanque dosador exerce.

Como no primeiro tanque está a dosagem de solução alcalina para mudança e controle de $\mathrm{pH}$, é necessário uma agitação rápida, o que consequentemente exige uma potência maior. O tempo de residência para esta operação é de aproximadamente 2,5 minutos, valor obtido através da Equação (9). Ao chegar ao tanque 2, a água receberá a adição de floculante e auxiliar de floculante - também chamado de polímero aniônico -. Neste tanque espera-se a formação de flocos pela ação do floculante e arraste das partículas pela ação do auxiliar de floculante. 
Experimentalmente, no tanque 2, é possível visualizar o início de sedimentação, o que podemos denominar de frente de sedimentação ou formação de clarificado inicial. Para esta etapa é utilizada uma velocidade de rotação intermediária e um tempo de residência de 2,9 minutos. Enquanto que no tanque 3, o afluente que recebeu os produtos irá sofrer uma agitação lenta para que não haja a fragmentação dos flocos formados, tornando o processo de sedimentação menos eficiente. Para isto, são requeridas apenas $0,5 \mathrm{~W}$ de potência e uma velocidade de rotação de $20 \mathrm{rpm}$, porém o tempo de residência é de 9,15 minutos.

\section{CONSIDERAÇÕES FINAIS}

Com os parâmetros apresentados, testados e obtidos em laboratório em trabalho complementar a este, torna-se possível a formação de flocos, posterior sedimentação e filtração, com obtenção de clarificado para ser utilizado no processo de beneficiamento de arroz. Consequentemente, a água de processo adequada promove a qualidade do produto final e corresponde às exigências econômicas e as requeridas pelos órgãos ambientais.

\section{REFERENCIAS}

CREMASCO, Marco Aurélio. Operações Unitárias em Sistemas Particulados. São Paulo: Blucher, 2012. 423p.

FONTANA, O. A. Sistema de Leito de Drenagem e Sedimentador como Solução para Redução de Volume de Lodo de Decantadores e Reúso de Água de Lavagem de Filtros - Estudo de Caso ETA Cardoso -. São Carlos, 164 p., 2004. Dissertação (Mestrado) - Universidade Federal de São Carlos.

GEANKOPOLIS, C. J. Transport processes and unit operations. 3 ed., New York: Prentice - Hall, 1993, $921 \mathrm{p}$

MCCABE, Warren L.; SMITH, Julian C.; HARRIOT, Peter. Unit Operation of Chemical Engineering. New York: Mc Graw Hill: High Education, 2005. 1140 p.

SEYDELL, T. M. Elaboração de Projeto de ETE para o Tratamento de Esgotos Urbanos do Município. Disponível em:< http://www.lindoia.sp.gov.br/up_anexos/Projeto\%20ETE.pdf $>$. Acesso em: 09 dez. 2013.

VON SPERLING, Marcos. Introdução à Qualidade das Águas e ao Tratamento de Esgotos. UFMG: Minas gerais, 2005. 